\title{
DESTINO Y DETERMINACIÓN EN EL NATURALISMO DECIMONÓNICO${ }^{1}$
}

\author{
$\mathrm{M}^{\mathrm{a}}$ ÁNGELES VARELA OLEA \\ Universidad CEU San Pablo
}

\begin{abstract}
Resumen
El Naturalismo del S.XIX aspiraba a convertir la literatura en ciencia, basando su "novela experimental" en la idea de que las leyes sociales nos determinan. El objetivo de este artículo es analizar ese determinismo y su semejanza con la idea griega de destino, subrayando el alcance más radical del fatum naturalista y de la subsiguiente visión de la responsabilidad, de la conciencia o del sentido de la acción humana.
\end{abstract}

Palabras clave: Determinación, destino, Naturalismo, ciencia, novela experimental, polémica, Taine, Bernard, Zola, Goncourt, Maupassant, Huysmans, Valera, Pardo Bazán, Galdós, Clarín

Destiny and determination in Nineteenth Century Naturalism

\section{Abstract}

In the mid of $19^{\text {th }}$-century, French Naturalism attempts to transform Literature into Science, creating "the experimental novel". This is based upon the idea that our actions are determined by social laws. The aim of this article is to examine this determinist view and to highlight the more radical reach of Naturalist fatum, in contrast with the Greek idea of destiny, and the subsequent belief about responsibility, conscience and the sense of human action.

Key words: Determination, Destiny, Naturalism, Experimental Novel, Science, controversial, Taine, Bernard, Zola, Goncourt, Maupassant, Huysmans, Valera, Pardo Bazán, Clarín.

\section{LA FILOSOFÍA DEL NATURALISMO}

El naturalismo literario surge como plasmación artística de un pensamiento común que Zola definió teóricamente. La escuela naturalista se propone la plasmación artística de una filosofía nacida contra los excesos del sentimentalismo romántico y que pretende poner en primer plano lo racional. La nueva prioridad del escritor naturalista es hacer una literatura de pretensiones científicas sustentada sobre un pensamiento concreto, que analizaremos.

Así lo exponía entre otros Guy de Maupassant, quien describía el ánimo general de los naturalistas reunidos por Zola en su casa de Medán, reconociendo su común

\footnotetext{
${ }^{1}$ Universidad CEU San Pablo. Correo: anvar.ihum@ceu.es. Aceptado: 02-03-2011.
} 
reacción contra el sentimentalismo compasivo y la idea de "perdón"2. Maupassant habla de la unión de todos estos escritores por la afinidad de temperamentos y sentimientos, así como por la tendencia filosófica común.

Uno de los objetivos prioritarios que este grupo naturalista se marcó era la eliminación de la moral romántica que arrastra una "sensiblería misericordiosa y sentimental”, arrancando de Francia la justicia, la lógica, el viejo sentido común escribe Maupassant.

Su erradicación del sentimiento personal hacia el ser retratado conduce a la impasibilidad del estilo naturalista, es decir, a la adopción de una frialdad científica por parte del narrador ante la situación de las criaturas retratadas. El sentimiento del narrador o autor no interesa, sólo los hechos objetivamente reflejados.

La observación y descripción verídica era ya propia del realismo, pero el antiguo observador realista pasará ahora en la nueva novela a ser científico. El texto literario dejará de ser únicamente la constatación de los fenómenos que el escritor tiene ante los ojos, para pasar a experimentar con lo observado. Así, el escritor es ahora un "experimentador" que anticipa una tesis e "instituye la experiencia" para que "ofrezca un resultado que sirva de control a la hipótesis o idea preconcebida" (Zola, 1989: 35). Así quedaba definida la denominada "novela experimental", basando su doctrina en Comte, Darwin y Taine, y poco después, en las teorías del médico Claude Bernard y su Introducción al estudio de la medicina experimental. Lo que González Herrán resumía como una síntesis de positivimo, cientifismo, darwinismo y experimentalismo. Como afirma el crítico, del positivismo toma la concepción general de su pensamiento, pero también una "confianza ilimitada" en las posibilidades de la ciencia (González Herrán, 1989: 10).

Taine, amigo y corresponsal de Zola, había propuesto la devaluación de la imaginación literaria, señalando los tres factores que caracterizan al individuo y que el escritor aplicará a los personajes: la raza, es decir, las disposiciones innatas y hereditarias que el individuo lleva consigo, el medio, ya sea físico o social, y el momento ${ }^{3}$. Y dado que la ciencia experimental conduce a un conocimiento positivo de los fenómenos, la metodología escogida es la "experimental” de Bernard.

La novela reflejará científicamente la conducta humana, que así entendida, se reduce a fenómenos dependientes de aquellos factores fundamentales. El papel del escritor pasa a estar limitado por la ciencia, pues una vez determinados ciertos factores, el personaje carece de libertad. Por tanto, el cometido del naturalista, en

\footnotetext{
${ }^{2}$ Guy de Maupassant en "La génesis del libro" - con que suelen prologarse Las veladas de Medan - explicaba ese ánimo común de los autores de las diferentes historias reunidas en el volumen. Los naturalistas se proponen combatir el sentimentalismo romántico, pues se ha "sustituido la idea de perdón por la idea de justicia, sembrando en nosotros una sensiblería misericordiosa y sentimental que ha reemplazado a la razón."

${ }^{3}$ Centrándose en la herencia de Taine en la escuela naturalista, especialmente en la obra de Zola, vid. (Huertas Llull, 1984: 29-52).
} 
síntesis científica de L. Alberti, es el cometido del experimentador que nada crea, salvo al instituir su experimento:

\begin{abstract}
De estos tres contenidos, el novelista científico solamente puede, a voluntad, operar en todo momento sobre el medio. Sus protagonistas pueden ser situados en un medio o en otro o incluso puede variar el ambiente en la vida teórica de un mismo protagonista. Respecto a la herencia, puede el escritor elegir el punto de partida, pero, una vez adoptado, el resto tiene que ser estrictamente el desarrollo de la primera proposición ateniéndose a las teorías de la herencia vigentes. El temperamento de los personajes le viene dado al novelista por el desarrollo hereditario y escapa, en buena parte, a su experimentación. La imaginación del escritor va a quedar limitada al planteamiento de los desarrollos. Lo demás viene a ser fiel información científica de la Biología vigente en su tiempo (Huertas, 1984: 47, cit. Alberti, 17).
\end{abstract}

En teoría, el papel de la imaginación del autor debe ser prácticamente nulo4. El escritor científico escoge el punto de partida de su experimentación, pero el desarrollo novelístico se ha de atener a los fenómenos sociales y a un temperamento de sus personajes que también le viene dado por herencia amoldada al medio. Zola sigue las teorías degeneracionistas del momento, las cuales exponían el carácter hereditario de los rasgos psíquicos, de caracteres morfológicos, de enfermedades adquiridas y hasta de comportamientos éticos inadecuados. El escritor toma de Morel su idea de una "herencia poliforma", la que los Rougon-Macquart sufren, y por la cual hay cambios generacionales en sus taras biológicas que van variando en sus manifestaciones sin que tengan que ver con las de origen. Es aquí donde el experimentador Zola tiene "más posibilidad de acción", porque a partir del vicio del alcoholismo "en las generaciones siguientes se metabolizará hasta transformarse en los distintos protagonistas en locura homicida, epilepsia, vicio, genio, etc." (Huertas, 1985: 137-8).

Bernard en el plano médico y Zola, en el literario, defendían la necesidad científica de acabar con lo indeterminado para lograr someter a leyes científicas los hechos. La idea de Taine heredada por los naturalistas de que la tarea artística ha de ser científica, se traduce en la eliminación de lo ideal, de lo sobrenatural, de lo espiritual, dado que por ser indeterminado resulta ajeno a las leyes que maneja el empirismo.

\title{
2. EL DETERMINISMO DE LA “NOVELA EXPERIMENTAL”
}

Cuando la escuela naturalista había publicado ya muchas de sus novelas fundamentales - doce años después de Teresa Ranquin -, su mayor artífice y teórico decidió publicar el ensayo titulado La novela experimental (1880). En esta obra, Zola expone claramente las claves del determinismo como la ley que rige los fenómenos que el escritor refleja en su novela. Así, no solo las leyes de la herencia, sino también, como veíamos, el medio social e histórico y la selección de las especies son las claves para explicar al ser humano y su sociedad:

creo que la herencia tiene mucha influencia en las manifestaciones intelectuales y pasionales del hombre. También doy importancia considerable al medio ambiente. Tendríamos que abordar

\footnotetext{
${ }^{4}$ A pesar de que, efectivamente, la fórmula naturalista se agotó pronto, lo cierto es que la exposición teórica del pensamiento naturalista no se aplicó de modo tan radical, ni siquiera por Zola, su mayor defensor.
} 
las teorías de Darwin; pero esto no es más que un estudio general sobre el método experimental aplicado a la novela y me perdería si quisiera entrar en detalles. (Zola, 1989: 44).

Y así como el divulgador del método científico - C. Bernard - consideraba imprescindible el estudio del medio intraorgánico, "si se quiere encontrar el determinismo de los fenómenos en los seres vivos", Zola establece que ese medio en una familia es el social. Herencia, medio, momento histórico, raza, sexo... El determinismo zolesco alcanza el mecanicismo: Los sentimientos humanos son también explicables como mecanismos que podremos descifrar y controlar.

Zola tiene una fe absoluta en la fisiología, pues "un día nos explicará sin duda el mecanismo del pensamiento y de las pasiones". Con una certeza algo menos tajante, llega a afirmar que el medio "seguramente" es "cuestión de física y química". Y aunque Bernard expone la dificultad de aplicar el método experimental en el estudio de los seres vivos - sobre todo en los animales superiores - , los naturalistas se proponen utilizar la novela como experimento científico para el conocimiento del hombre. Zola toma la idea de Bernard de que "solamente en las condiciones físico-químicas del medio interior encontraremos el determinismo de los fenómenos exteriores de la vida" (Zola, 1989: 46). La novela, como la ciencia, no se debe ocupar del porqué de los hechos, sino del cómo.

Este determinismo absoluto se aplica de modo universal, anterior incluso al nacimiento de los seres retratados y acompañándolos en cada momento, dejando un estrechísimo margen a la creación artística, pues, como decíamos, el experimentador naturalista tan sólo escoge el punto en que ha de poner a sus criaturas para anotar el desarrollo que le viene dado según las teorías científicas del momento. En aras de la denuncia social, el escritor puede escoger un medio $u$ otro, un sexo $u$ otro, pero luego relatará lo que le está determinado por esas leyes, amparado por la frialdad narradora del científico que anota el comportamiento de su criatura literaria ante los estímulos ambientales que le son propios.

Dadas las premisas ideológicas y el afán de denuncia social de estos escritores, el protagonismo de sus novelas recae en las clases más desfavorecidas, limitadas por sus escasas posibilidades económicas y sociales, y más fácilmente reductibles a esas leyes, puesto que es mayor su incapacidad de ejercer elecciones. En ese sentido, aflora con mayor inmediatez la determinación en mujeres o niños. Por eso, de entre los más menesterosos, un elevado tanto por ciento del protagonismo de estas novelas recae en mujeres, puesto que aunque biológicamente sean adultas, su supeditación emerge y comparece narrativamente con cortapisas que ni los varones sufren. Así, la mujer aparece determinada por factores biológicos y sociales -como su dependencia económica, su falta de instrucción, su dificultad de acceso a un oficio digno, etc. - , y estos factores hacen que sea sexualmente objetificada. En una lucha por la supervivencia, la desigualdad manifiesta de estas mujeres establece relaciones de poder que valoran únicamente su materia, por lo que el cuerpo femenino es medio de empoderamiento que, no obstante, conduce a la destrucción de todo y todos. 
La universalidad del determinismo expuesto por Zola -anterior por leyes de herencia al nacimiento, presente en todo momento y a todo lo existente - era difícil de aplicar en la práctica novelística con el rigor que exigía la teoría. Ciertamente, siendo la novela de Zola la de mayor calidad y originalidad de la escuela, y también la más rigurosa en la aplicación de estas ideas, transmite con un talento poco común cómo un ser inanimado puede aparentar más voluntad que los seres humanos: piénsese, por ejemplo, en la mina de Germinal descrita mediante personificaciones, en tanto que sus trabajadores son objetivados. Detractores del naturalismo como Valera, hacían ver una y otra vez lo absurdo del absolutismo de ese determinismo que, teóricamente, debía afectar igual a seres animados y a objetos inanimados, "a la piedra del camino y al cerebro del hombre". Los contemporáneos que atacaban la escuela naturalista con mayor conocimiento no rechazaron únicamente el estilo de su expresión, sino la confluencia en esta novela de corrientes pesimistas y materialistas (López Jiménez, 1977: 144 y 229).

\section{LA VISIÓN NATURALISTA DE LA EXISTENCIA HUMANA}

La propuesta teórica de Zola expresa una radicalidad no siempre puesta en práctica del mismo modo. No obstante $-\mathrm{y}$ con excepciones de autores, obras o personajes de una misma obra - , ciertas notas comunes nos permiten una visión global respecto a cómo entienden los naturalistas el papel del hombre en el mundo. Según esta concepción determinista del ser humano, en el devenir no comparece la voluntad, pues de todas formas somos construcción -montaje de nuestras determinaciones - en que la libertad queda atrapada entre las redes de nuestras circunstancias. Así, los personajes de la novela son sumisos y hasta insensibles, con inteligencias atrofiadas por trabajos o medios embrutecedores (Maupassant, Zola, Huysmans, Goncourt; algunos de Pardo Bazán o Galdós $\left.{ }^{5} . ..\right)$, nacidos para la alienación social o mental (Jules Vallès: SainteAnne; E. Goncourt: La ramera Elisa; Zola: La bestia humana; Galdós: La desheredada) o en el mejor de los casos, para la mediocridad y miseria materialista (Huysmans: Mochila al hombro / Con el petate a cuestas ${ }^{6}$ ). Por eso, los seres humanos aparecen acostumbrados a la "esterilidad de la reacción" (Maupassant: Bola de sebo), "bajo la idea hereditaria de sumisión y pasividad" (Zola: Germinal), que frecuentemente se "contentaban con

\footnotetext{
${ }^{5}$ Embrutecen los trabajos físicos, pero también los de las oficinas como vemos en Maupassant o Huysmans. En Los pazos de Ulloa, por ejemplo, Perucho aparece bestializado, sin que, al comienzo, podamos diferenciarlo entre los perros con quienes come. También sus padres son bestias animalizadas. No obstante, Perucho evoluciona y escapa de su "destino", en parte, precisamente por la presencia en la novela de seres espirituales como el sacerdote. En La desheredada galdosiana, "Pecado" es un personaje en quien se refleja esa determinación de la herencia, del medio, de la educación, del momento... de ahí, su final criminalidad y estupidización. Pero en la misma novela, personajes cervantinos como Miquis, vencen sus inclinaciones y son ejemplo de libertad. Las novelas españolas de los grandes intelectuales atemperan mucho esa influencia, salvo parcialmente Blasco Ibáñez o casos de escasa calidad de un naturalismo folletinesco, como los de López Bago o Sawa.

${ }^{6}$ Los títulos de las obras de Huysmans han sido traducidos de diversas maneras. En la edición de Cobos (2003) aparece con el título Con el petate a cuestas, aunque es más frecuente oírla nombrar como Mochila al hombro, como aparece en la ed. de Cardoso (1977).
} 
mirar" cómo se les acerca la muerte, o cómo otros muertos caen cosificados como bultos a su lado (L. Hennique: El asunto del número siete; Zola: El ataque del molino) ${ }^{7}$.

Como consecuencia, resulta inútil todo esfuerzo. Los personajes son, en palabras de Zola, "bestias humanas" cuyo grado en la escala de los seres vivos puede llegar a ser el mismo que el de los objetos inanimados. Algunos personajes femeninos llegan a ello, de estar tan embrutecidos por el vicio, carentes incluso de la voluptuosidad que se les presuponía. Así, en referencia a una prostituta, se llega al grado de describirla como "animal alegre y semi cuadrumano", ser insensible y bruto encerrado en una piel humana (E. Goncourt: La ramera Elisa). La determinación de estos seres es tan universal que carecen de la voluntad hasta para los pequeños actos cotidianos. Como los seres inferiores que nos han descrito, lo que los mueve y tienen es instinto y pulsión animal: las "pocas ideas" de los personajes son obsesivas y los "asaltan"; habitualmente resignados, a veces parece que van a reaccionar a causa de un "viento de rebelión", pero luego éstos vienen a ser actos "impulsivos" motivados por una enfermedad heredada genéticamente a causa del alcoholismo (Zola: La taberna, Germinal). Incluso sus pequeños gestos animalizadores, como rascarse cualquier parte del cuerpo a pesar de estar siendo observados, son fruto de ese "impulso" que el personaje - dice el narrador - "no podía contener" (Maupassant: En familia).

Los seres "humanos" - las criaturas literarias naturalistas - son incapaces de reaccionar contra poderosas fuerzas externas, aunque, de todas formas, cualquier reacción sería inútil. Edmund de Goncourt, por ejemplo, nos describe seres que llegan a lo más bajo por esa incapacidad: Elisa se hace prostituta por pereza, e incapaz de cualquier reacción, sus actos son decididos sin su voluntad: como animal instintivo, pasa de prostíbulo en prostíbulo sin saber a qué obedece el aburrimiento que la lleva, sin saber si quiera qué le impulsa al peregrinaje. El alcohol, el ruido ensordecedor, el encanallamiento progresivo y buscado, ayudan a no pensar en la completa ausencia de medios de defensa, de intereses y de nociones de las cosas. La novela naturalista se puebla de seres que, como Goncourt escribe, se aproximan intelectualmente "a un grado inferior de la especie humana" (Goncourt, 1998: 73). Los mineros de Germinal resultan menos voluntariosos que la propia mina asesina que los devora, engulle y escupe. Se reproducen, emborrachan, mueven o comen por instinto de supervivencia. "Todas" las cargadoras hacen sus hijos y futuros mineros "tumbadas" por sus borrachos compañeros de trabajo (Zola, 1972: 134). El medio se impone y los mineros, de generación en generación, no se plantean otra cosa que no sea la inercia de la taberna y la mina, aunque al menos, ellos son quienes "tumban" a las mujeres, objeto pasivo de su acción sexual instintiva, también desde siempre.

\footnotetext{
${ }^{7}$ Por no extender el análisis y ofrecer una visión de conjunto de los seres que pueblan los relatos naturalistas, me permito extractar frases de los textos y autores indicados entre paréntesis: cito además de novelas como Germinal, Naná o La taberna de Zola, Los Pazos de Ulloa de E. Pardo Bazán, Río abajo y Las hermanas Vatard de Huysmans, Germinie Lacerteux de los hermanos Goncourt, La ramera Elisa de Edmund de Goncourt, relatos de colecciones como Las veladas de Medan (2003) de ella: El ataque del molino de Zola, Con el petate a cuestas de Huysmans, El asunto del número siete de Hennique y Bola de sebo de Maupassant y de la colección de relatos titulado El cuento naturalista francés (1977): En familia de Maupassant, SainteAnne de Jules Vallès y de Huysmans, Mochila al hombro.
} 
La Madame Pahauen de Ceárd -La sangría - o la Naná de Zola ofrecen una variante distinta dentro de la misma ley: la de la prostituta que lo es, ahora, por vicio. En tal caso, la lucha por la supervivencia y por el dominio de la especie, determinan la instrumentalización del cuerpo como arma de poder. Pero, como la Elisa de Goncourt, experimentan el aburrimiento del vicio, buscando en el encanallamiento exterior la cura para la insaciabilidad interior. El naturalista se había propuesto la observación de una variante de la especie, y el resultado es una destrucción aún mayor: no sólo ya la propia, sino la de todos y todo.

En esa búsqueda de ejemplares diversos en los que ejemplificar en la novela las leyes que determinan a los seres humanos, un autor nos revela más explícitamente que existen también otras fuerzas interiores que desde dentro pueden abatir al ser humano: ese será el peculiar epicentro novelístico del Huysmans naturalista. Para este nuevo tipo de fuerza que se le impone al hombre, además, no es necesario pertenecer a la clase más miserable, tener la peor de las educaciones, la enfermedad o tara más extraña, el pasado más trágico y el destino más aciago. Pero también en este caso, resultará inútil luchar contra ella, pues también el spleen nos aplasta aunque ahora desde el interior y nos conduce al destino gris de la inercia y de la abulia.

A las anteriores determinaciones habituales entre los naturalistas, Huysmans, en su fase naturalista, añade una fuerza más contra la que el individuo no puede luchar y que actúa en dirección contraria a la que nos describían los demás escritores de la escuela: de dentro afuera. Ese hastío puede llegar a convertirse en una fuerza más poderosa que la guerra, la enfermedad o la miseria (Mochila al hombro; Huysmans, 1977, 2003). En las batallas cotidianas contra las fuerzas externas, esa opresión interna aparenta calmarse, momentáneamente, con la saciedad de los sentidos en comilonas, relaciones superficiales meramente sexuales o conversaciones, en tiempos de guerra, sobre estética (Huysmans, Río abajo, Mochila al hombro... y en ese sentido, A contrapelo). Los personajes se dejan llevar por fuerzas extrañas a ellos mismos, son existencias "a la deriva", sin libertad ni oportunidad para ejercerla ${ }^{8}$.

La determinación del ser humano es su cárcel, condena que se paga por nacer y desde ese mismo momento, tópico extendido desde Plinio: "el felizmente neonato yace atado de pies y manos [...] y empieza su vida con suplicios por una sola culpa, porque ha nacido" (et a suppliciis vita auspicatur unam tantum ob culpam, quia natus est ${ }^{9}$ ). Así, aquellos locos que osan desafiar el encierro en que nacemos pagan consecuencias nefastas. A veces, algunos individuos se atreven a soñar y a aspirar a tener una vida diferente, en otra clase social y circunstancias distintas a aquellas de la que son

\footnotetext{
${ }^{8}$ El personaje autobiográfico de Mochila al hombro de Huysmans permanece confinado en hospitales durante la guerra, desea salir de ellos para sofocar esa angustia, pero dado que esa fuerza es interna y no externa, una monja le espetará: “¡Oh, la libertad no le serviría para nada!” (Huysmans, 1977: 125).

${ }^{9}$ Los escritores españoles conocían perfectamente el tema, pues Calderón, en La vida es sueño, había expuesto magistralmente éste y otros planteados por el naturalismo, como el lugar del hombre en el mundo y su libertad como diferencia esencial respecto a seres animados e inanimados o el delito del hombre por haber nacido. Todo este debate intelectual, herencia de la Contrarreforma, frenará el impulso del naturalismo entre los intelectuales españoles. Sobre la herencia de Plinio y su influencia en Calderón, vid. Ynduráin, en (Calderón, 2004: 33-36).
} 
prisioneros. Esos individuos son los que peor acaban. Si es prostituta y por primera vez sale de su estado infrahumano y aspira al sentimiento, acabará, por ejemplo, ejecutada (La ramera Elisa). La prisión, el manicomio o la enfermedad son sus destinos. Con frecuencia, quienes han querido escapar de la miseria o sencillamente, de un destino convencional y de las circunstancias que les tocaron al nacer, son encerrados en una institución psiquiátrica $\mathrm{y}$, como los seres observados por Jules Vallès, niegan a gritos su locura. Para estos ilusos hubiera sido mejor no resistirse, puesto que esa actitud sólo empeora su situación (Sainte-Anne; Vallès, 1977: 88). Vallès nos advierte: La cabeza de cualquiera de nosotros puede estallar, y en los últimos años, el mal crece incesantemente. El comportamiento del loco es intermitentemente ordenado, es en esos momentos de cordura cuando: “Cada uno ocupa un lugar determinado y sabe encontrar el camino" (Vallès, 1977: 102).

La cuestión de la mujer en la novela naturalista incurre en varios extremos: Por un lado, la negación de la voluntad como fuerza capaz de superar la determinación la condena a su sumisión perpetua. El fatalismo de los fenómenos, como manifestación del determinismo, provoca la abulia inoperante, la resignación respecto a la situación que le es dada. La esterilidad del esfuerzo deviene en la inercia de las fuerzas que coadyuvan a su minusvaloración. Y el materialismo de la escuela que interpreta al hombre como ser desespiritualizado por el medio y el trabajo, se traduce en una visión del ser humano animalizada, y en el caso de la mujer, reducida a su materia corporal que, en medio social como el que estudiamos, significa su valoración a ojos del jefe de la especie, el macho. De ahí, la imagen de la mujer como cuerpo sexuado, objeto pasivo de los deseos masculinos. Y en la rara ocasión en que es ella jefe de la manada -por ejemplo, en Naná, en La sangría o en Bola de sebo - , asistimos a su ascenso como tal gracias a la instrumentalización del cuerpo sexuado en aras del intercambio de poderes, lo que en la novela del siglo XIX es su capitalización en la cortesanía o en la prostitución ${ }^{10}$.

Muchos coetáneos rechazaron las teorías de los naturalistas, así como el estilo en que se traducía el objeto preferente de sus novelas. La negación naturalista de trascendencia, el exacerbado materialismo y ese determinismo que negaba el libre albedrío chocaban de frente con tradiciones culturalmente cristianas como la española. Aquí apenas triunfó el naturalismo, y salvo en unos pocos autores -Blasco Ibáñez - , generalmente de escasa calidad -López Bago o Sawa-, lo que se dio fue un aprovechamiento de ciertas técnicas tomadas de la escuela, además del frontal rechazo al pensamiento de fondo de los naturalistas (Pattison, 1969 y Martínez Torrón, 1987: 589-95).

\footnotetext{
${ }^{10}$ En este sentido, es de valorar la difusión popular que gozó está novela y el extenso legado aún hoy vigente, en parte, gracias a que la frialdad narradora aplicada a lo sexual permitía lecturas pornográficas que sus autores no buscaban pero a veces fomentaban.
} 


\section{LA POLÉMICA RECEPCIÓN DEL DETERMINISMO NATURALISTA}

Fueron muchos los motivos por los que el Naturalismo despertó la polémica entre sus coetáneos. Uno de los más frecuentes fue su desgarrado estilo; lo que en genial síntesis, Huysmans denominó su “cucarachismo” (Huysmans, 1919: 47-8).

Pero algunos más atentos al fondo que a la forma advirtieron que lo realmente difícil de aceptar era el fondo de su pensamiento, (entre ellos, el propio discípulo de Zola $\left.^{11}\right)$. Los novelistas naturalistas raramente teorizaban o explicitaban esas ideas, dado que habían escogido como género la novela, no el ensayo. La mayoría de los lectores conocieron posteriormente estas teorías, como le sucedió a la propia E. Pardo Bazán, su introductora en nuestro país. El pensamiento naturalista que aparece en prólogos y artículos (y raramente en ensayos) corresponde en su medio natural a la práctica novelística.

Así pues, el lector llega al naturalismo a través de sus novelas, en las que ese pensamiento y estilo quedaban desarrollados, pero, este primero, también diluido. De ahí las interpretaciones a que dio lugar más o menos certeramente y que escritores como Zola matizaron o explicaron teóricamente a posteriori. La lectura de historias sobre hombres reducidos a bestias humanas, luchando con los otros ejemplares de la especie en aras del instinto de supervivencia, el cuadro de pobreza que permanentemente terminaba en tragedia, la cosificación del ser humano, sin voluntad ni capacidad para evitar los hechos, la galería de males y enfermedades sociales que retrataban estas novelas y la invariabilidad de aciagos sucesos de los personajes naturalistas, provocó que la novela naturalista se interpretase como el resultado de la creencia en una ineludible predeterminación o destino. Para aumentar la semejanza aparente entre el destino griego y el determinismo naturalista, pronto se habló de la facilidad con que el lector podía adivinar el destino de estos personajes. Sin necesidad de oráculos, el análisis permite no ya la adivinación, pero sí el pronóstico sobre el futuro de los personajes.

Así, escritores de la propia escuela como Huysmans abandonarán este modo de novelar precisamente por ser conscientes del agotamiento de una fórmula que hacía predecibles los destinos de los personajes. El médico y el escritor protagonistas de su novela Allá lejos (1891) coinciden en que los monótonos estudios de seres mediocres y los interminables inventarios de datos con que los naturalistas pintaban el medio conducen "en línea recta a la esterilidad más completa" (Huysmans, 1919: 48).

Como decíamos, en España varios lectores avezados advirtieron que su rechazo frontal al naturalismo no lo era únicamente por la forma, sino por el fondo. El escritor y crítico Luis Coloma ya advirtió que nuestros escritores españoles -en referencia a los grandes autores - no habían tomado de la escuela más que la forma: La gran diferencia respecto al "realismo tradicional en nuestras letras" radica en "el fondo filosófico de sus doctrinas. El que no sea determinista, fatalista y materialista no puede aceptar

\footnotetext{
${ }^{11}$ En el mismo diálogo de Huysmans, el personaje también toca este asunto y subraya que más allá del estilo, lo más reprochable de la escuela es precisamente su incapacidad para atender a lo espiritual; ajeno a lo elevado, el escritor naturalista reduce su labor a la de un "braguerista del alma".
} 
el fondo de Zola" (González Herrán, 1989: 86). Así, Valera se mofaba del término "experimental" con que estas novelas se tildaban, pues no veía experimento alguno en la constante narración de historias de muchachas que como las de Goncourt, Zola o Paul Alexis, "como mil otras", acababan de meretrices "desaforadas" (Valera, 1886: 332). Y es que, si es mujer, el personaje parece destinado a la prostitución.

En respuesta a quienes hablaron del naturalismo como una versión moderna del fatalismo, Zola matizó que causa y consecuencia no son lo mismo: Lo que la lectura de las novelas puede considerarse erróneamente como fatalismo, es consecuencia de la interpretación determinista de la existencia, propia de la escuela:

Hemos dado el nombre de determinismo a la causa próxima o determinante de los fenómenos. No actuamos nunca sobre la esencia de los fenómenos de la naturaleza sino sólo sobre su determinismo, y por el hecho de que actuamos sobre él, el determinismo difiere del fatalismo sobre el cual no se puede actuar. El fatalismo supone la manifestación necesaria de un fenómeno, independientemente de sus condiciones, mientras que el determinismo es la condición necesaria de un fenómeno cuya manifestación no es obligada. Una vez que la búsqueda del determinismo de los fenómenos está puesta como el principio fundamental del método experimental, ya no existe ni el materialismo, ni el espiritualismo, ni materia bruta ni materia viva; no hay más que fenómenos cuyas condiciones hay que determinar. (Zola, 1989: 52)

Se trata de aplicar la filosofía natural, dice Bernard, "conocer la ley de los fenómenos" (Zola, 1989: 47). El escritor naturalista observa la causa determinante -el medio, la herencia, el momento - y experimenta con esas condiciones necesarias, sin alterar los fenómenos.

Para el naturalista es imprescindible creer en la existencia de una "ley", puesto que sin ella no podría pretender hacer ciencia. El determinismo es esa ley, esa constante inalterable $\mathrm{Al}$ aceptar el determinismo, se puede deducir una ley que sirva al científico -médico o novelista - para controlar los fenómenos individuales y sociales.

Como en el mito de Prometeo, Zola piensa que la ciencia hará al hombre "todopoderoso" -escribe-, capaz de ser amo de las enfermedades y de dominar la Naturaleza. Muerto el "hombre metafísico", la gran transformación llegará con el "hombre fisiológico". La cólera de Aquiles o el amor de Dido pasarán a ser bellas pinturas, pues la nueva novela deberá analizar el amor y la cólera (Zola, 1989: 71). Subyugado por el poder de la ciencia, considera que proporciona al hombre la oportunidad de "ser amo del bien y del mal, regular la vida... resolver a la larga todos los problemas del socialismo" (Zola, 1989: 41).

\section{SEMEJANZAS Y DIVERGENCIAS ENTRE EL DESTINO CLÁSICO Y EL DETERMINISMO NATURALISTA}

El determinismo naturalista que analizamos es un determinismo absoluto para autores como Zola: combinación de diversas leyes, que en su aplicación novelística y en su teoría llega al mecanicismo. Lógicamente, y del mismo modo que no todo autor clásico atribuía al destino la misma inexorabilidad, tampoco fue así respecto al determinismo. Ahora bien, la novela naturalista se define y nace de la conjunción sistemática del determinismo biológico y del sociológico. 
Obligados por un escueto estilo científico, el eco de los clásicos resuena únicamente de vez en vez en las obras de estos escritores decimonónicos. En algunos como los Goncourt, en fase precursora del naturalismo, el determinismo del personaje no es incompatible con la conmiseración hacia sus desgracias. La degradación de Germinie Lacerteux no extirpa en ella los sentimientos, o en sus autores su deseo de describir datos ajenos a la ciencia experimental (pues el personaje se basaba en un ser real que les era próximo). Una vez muerta Germinie, su antigua señora reflexionará sobre la existencia de su criada, interpretando su desgraciada vida como la de una víctima de los acontecimientos, de sus circunstancias, de la fisiología o hasta del destino. Determinismo y destino se entremezclan y confunden:

Se preguntaba si la pobre chica era tan culpable como otras, si había escogido voluntariamente el mal camino, si la vida, las circunstancias, su cuerpo enfermizo y su malhadado destino habían hecho de ella la criatura que había sido, un ser para el amor y el dolor... (Goncourt, 1990)

De entre los factores que condujeron a Germinie a una vida de miserias, surge el malhadado destino como una de las causas que la hizo "un ser para el amor y el dolor". Una vez sentenciada la humilde criada, expuesta su existencia como consecuencia del sufrimiento y del amor, los Goncourt parecen tener en mente la célebre frase de Antígona increpando a Creonte precisamente que no nació "para el odio, sino para el amor" (Sófocles, 1990: 392).

La ramera Elisa es el texto fundador de la novela naturalista con esa tendencia filosófica-fisiológica a la que pertenecen posteriores novelas como Naná o La taberna (Botrel, 1988: 183-197). En ellas, lo fisiológico sustenta el pensamiento que hemos definido, siendo la ley de determinación que más se deja sentir en el estilo. Pero también un fatum clásico opera de fondo: la maldición del destino de las prostitutas persigue a la Elisa de Edmund de Goncourt. En esta novela, el destino es determinante, o más exactamente, la creencia en un destino, determina el comportamiento. En La ramera Elisa, una idea obsesiva e irracional angustia a la protagonista: la predicción fatal de una adivina que le vaticinó que el peso de la justicia caería sobre ella y la proximidad de su muerte. Ese destino conocido por quien lo siente al acecho actúa sobre Elisa, paradójicamente, siendo una fuerza más de su determinación.

Pero destino y determinación son realidades distintas, aunque literariamente puedan parecer muy semejantes. De hecho, la creencia en el destino es de origen religioso o propia del irracionalismo mitológico, en tanto que la determinación se basa en la sustitución de la religión por la ciencia y en la aplicación de principios racionalistas y lógico-positivos. Por tanto, en principio y teóricamente, serían opuestos. Ahora bien, aunque el destino clásico y la determinación naturalistas no sean lo mismo, en su desarrollo literario vienen a confluir, de suerte que incluso los escritores decimonónicos dejan a veces entrever esa idea de fondo.

Si sobre Layo, Edipo, Antígona o Jerjes se cernía una maldición inesquivable a cuyo conocimiento se podía acceder a través de oráculos y profecías sagradas, la nueva visión determinista del ser humano permitiría el conocimiento de su devenir a través de la ciencia. Zola lo dirá explícitamente: la ciencia viene a sustituir a Dios (creando la paradójica "religión del positivismo" que finalmente propuso Comte). 
Una vez pasada la parcial acogida inicial del naturalismo por parte de escritores españoles como Galdós, Clarín o Pardo Bazán -que tomaron de él elementos analíticos compatibles con su realismo-, este aspecto será el que cause un mayor rechazo. La que Caudet denominó para nuestro país “querella naturalista”, provocó descalificaciones e insultos que llegaron a lo soez (Caudet, 1988: 58-70). No sólo fueron muchos sus detractores, sino que sus iniciales defensores rechazaron la inflexibilidad de su determinismo.

En 1901, Clarín, por ejemplo, muestra un repudio casi total a las ideas de Zola y dice haberlo traducido únicamente "por espíritu de tolerancia". No sólo rechaza sus "aventuradas negaciones" de Dios, o del alma, sino sus ideas sobre la evolución, el fin de la vida o la llamada cuestión social. Pero lo que el español aún deplora más del francés es la inflexibilidad de su dogmatismo. Los españoles, más inclinados al espiritualismo que al cientifismo y al materialismo, rechazan la sustitución de Dios por la Ciencia, y señalan las limitaciones y peligros de esa nueva diosa ${ }^{12}$ :

Zola, como Augusto Comte, del cual es en Trabajo, en lo esencial, fiel discípulo, es un católico al revés; y así como se ha aprobado que el organicismo social positivista era una iglesia católica, con su papa a la cabeza, el mismo Comte; la utopía de Trabajo $^{13}$ es un catolicismo ateo y hedonista con su pontífice, Lucas. (Caudet, 1988: 63).

Otro factor fundamental da un carácter opuesto a ambas ideas: el hecho de que la idea griega de destino esté unida a la de trascendencia, en tanto que el determinismo se base en su negación. Los personajes griegos pueden adelantar su destino y dirigirse a él con la cabeza alta, porque el mal se acepta cuando no arrastra deshonor y la muerte lo es con gloria - como decía Etéocles-. Lo que los héroes griegos rechazan es la desdicha que llega con infamia. El ser humano puede tratar de congraciarse con su hado, aunque frecuentemente se nos repite que nadie escapa a los trances que los dioses envían. Ajax, Jerjes o Eteocles adelantan su destino, pues piensan que "es mejor morir pronto que tarde" (Esquilo, 1993: 68). Personajes como Antígona aceptan esas trágicas existencias pensando en que será más tiempo el que pasemos con los muertos que con los vivos. El destino puede ser tan trágico como el que persigue a su familia, pero la idea de la vida de ultratumba influye en las elecciones en esta vida, inclinándolas al valor, honor o gloria. El determinismo subraya el sinsentido del sufrimiento para quien lo padece, analiza su causación o consecuencias, pero el modo en que se afronta carece de importancia.

A pesar de esa inexorabilidad del Destino griego, se entrevera en la obra clásica la indeterminación del ser humano, máxime en casos de seres excepcionales como los que las tragedias y epopeyas retrataban. Aunque el final de la vida sea la tragedia, el camino de ese destino no es universal, no abarca cada detalle, y puede, por ello, ser un

\footnotetext{
${ }^{12} \mathrm{~F}$. Caudet expone cómo Zola, una vez terminado el ciclo novelístico naturalista, pasa al mesianismo. La última novela de los Rougon-Macquart terminaba afirmando: "Dans le temps troublés, on doit attendre les prophètes". Partiendo de la concepción determinista y finalizada su fase naturalista, Zola anuncia la nueva novela que iniciará: la de tesis y mesianismo (Caudet, 1991: 19).

${ }^{13}$ Novela de Zola que Clarín traduce y prologa, y a la que el español antepone esta diatriba. El protagonista es Lucas, alter ego ideológico de su autor, un fourierista humanitarista.
} 
ejercicio de libertad, limitado pero no determinado y con causas no reductibles y, por tanto, imprevisibles.

Para los clásicos, el dolor y el sufrimiento recuerdan la limitación de los seres humanos y su esencia mortal como tales, en tanto que los deterministas tan sólo consignan el fenómeno científico de la repetición sin sentido del dolor en las criaturas animadas, humanas o animales, y su inconsolable finitud. Ambas creencias son fatalistas, ahora bien, en tanto que para los griegos ese final terrenal es el pórtico de una vida de ultratumba en la que gozar de la fama y el agradecimiento de la eternidad y de los ya muertos, cuando los actos en vida así lo han merecido, para el "fatum naturalista" no hay virtud ni error, pues no hay libertad ni responsabilidad.

Creyendo los griegos en el destino, no creen en cambio en la determinación durante la vida terrenal, puesto que no creen necesariamente que todo lo que ha habido, hay y habrá está de antemano fijado por una universalidad que sí afecta al determinismo. Del determinismo de la teoría zolesca y de muchas novelas, podría decirse como de la fuerza del destino en Antígona que "Ni el dinero ni las armas / ni las torres ni las naves / pueden escapar al destino." (Sófocles, 1990: 406). Pero mientras para los griegos es así en aras del cumplimiento de esa porción de destino prevista, pero está esencialmente centrada en la muerte de los mortales, para el naturalista, el determinismo se cierne universalmente sobre el dinero, las armas, las naves o los seres. Aunque con variantes en sus atribuciones, el poder de las Parcas no tiene tanta concreción. Estas sostenedoras del orden son las encargadas de ejecutar el destino individual que, para los mortales es, como explica Ruiz de Elvira, "ante todo, la muerte". Su misterioso poder, denota una "coacción o compulsión ineludible aunque indeterminada". En ocasiones, a su poder quedan sometidos hasta los dioses, si bien, puede llegar a ser incluso negociable, según Apolodoro, Esquilo y Eurípides ${ }^{14}$ (Ruiz de Elvira, 1995: 61, 323). El comportamiento de los héroes puede influir en el destino. Así, viendo próximo un desenlace trágico, Etéocles duda si seguir congraciándose con su destino o precipitarse a su cumplimiento. El coro trata de convencerlo de que no se enfrente a su hermano, confiando en la clemencia de su sino y en que "el hado cambie de designios" (Esquilo, 1993: 69).

La jurisdicción del determinismo abarca todos los fenómenos del universo y es más propio de causas eficientes que únicamente de las causas finales, en tanto que, con variantes pero en general, el destino fija la confluencia de ciertas causas finales (telos) fundamentalmente orientadas hacia su finalización (péras) en la muerte. Etéocles, Jerjes, Antígona e Ismene no actúan conforme a unas leyes de causalidad que los exonere de responsabilidad. Por el contrario, la creencia en el destino no exime del error fatal (hamartia) o la hybris. Los trágicos griegos subrayan los errores de sus personajes y la parte de responsabilidad que tienen en el modo en que su destino se cumple. Jerjes, al tender un puente sobre el río Helesponto, y quebrantar la ley natural, anticipa su particular tragedia y la catástrofe persa profetizada. Etéocles conoce también su

\footnotetext{
${ }^{14}$ Pues ellos relatan cómo Apolo convence a las Parcas para cambiar el día fijado para la muerte de Admeto, si encuentra alguien que voluntariamente ocupe su lugar.
} 
destino por las profecías, y teniéndolo en cuenta, va a su encuentro. El coro acusará a Antígona de ser impetuosa, y esa hybris la responsabiliza parcialmente de sus males, que debería haber evitado y que ella misma decide capitanear, hasta el grado de ejecutar su propia muerte suicida. En la interpretación más radical del destino, Cloto -la Hiladora - , Láquesis -la que da a cada uno su lote - y Átropo - la Inflexibleseñalan y ejecutan las disposiciones con que se entreteje el inexorable destino. Pero ni siquiera en la versión hesíodica se niega que los seres participen de su destino, con el que se congracian o no, e incluso tratan de alterarlo con mayor o menor fortuna. En la creencia clásica, los seres son responsables respecto a lo no definido en ese "lote" y respecto a cómo se comportan conforme a lo sí establecido en él. Como se dice en Agamenón, es norma divina "que cada hado se atenga a su porción" (Esquilo, 1993: 162). Incluso, en un acto de voluntad los seres pueden decidir el modo o momento de su destino, en tanto que los personajes naturalistas actúan por fuerzas como la inercia o el instinto, y en el caso de que tengan conciencia, es probable que se dejen ganar por la abulia.

No obstante, en ambos casos y en expresión calderoniana, el final de sus vidas (terrenales) es el castigo al delito de nacer. Para los griegos, el modo de actuar difícilmente influye en lo designado, y es casi seguro que, hagan lo que hagan, será prácticamente imposible sortearlo. Para los deterministas no hay más modo de hacer que el que se hace.

En general, la idea de destino admite causalidades distintas: es decir, los fenómenos de la existencia humana suceden por mandato o por una maldición, que puede ser revelada por un oráculo. El modo en que se ejecute ese destino, puede variar, es posible que no esté totalmente fijado o designado en ese "lote" que nos corresponde. Así por ejemplo, con respecto a la familia labdácida, su destino dice que se aniquilarán a sí mismos, pero no necesariamente ahorcándose. Por el contrario, el determinismo no puede admitir diversas posibilidades de causación - simples o complejas, son las que son-. Gervais Macquart será alcohólica por varias causas que la determinan: por el medio, por la herencia, por la clase, por su sexo.... Por una serie de causas determinadas y determinantes, pero no por otras. Determinar es precisar, es negar: se excluyen todas las notas o características que no le pertenecen (decía Spinoza: Onmis determinatio negatio est). En cambio, la idea de destino se opone radicalmente al principio de causalidad, como Spengler subrayaba.

En ese sentido, resulta elocuente el modo en que los naturalistas se interesan por la complejidad causal de la locura. Varios escritores se proponen analizar la paradoja de la razón de la sinrazón, es decir, la razón de la manifestación fenoménica de la irracionalidad humana. Los autores naturalistas pormenorizan las causas por las que se producen los arrebatos violentos de Esteban (Germinal) o la locura homicida de Elisa o de Jacques Lantier (en La ramera Elisa y en La bestia humana); consecuencia de la herencia, del medio y dela historia. Y así comola primera llegó a ella, fundamentalmente, a causa del medio, de su clase o de su sexo, los personajes de Zola arrastran además la "alienación hereditaria", conforme a lo que exponían las investigaciones científicas sobre enfermedades mentales del momento (Huertas, 1985). La ley de la herencia se 
combina con otras leyes sociales para determinar la concreta manifestación fenoménica en los personajes retratados.

En alguna rara ocasión, el determinista halla un elemento de la realidad cuya causa se escapa a su comprensión. Entonces, el motivo de aquel fenómeno predecible aparenta la irracionalidad mitológica, la maldición del destino. Así como la ciencia explica la aparentemente indescifrable demencia, y el análisis de las vivencias de quien la padece nos explica si fue el vicio o la virtud lo que determinó la insania nos explica Vallès-, aquello racionalmente inexplicable queda atribuido al azar: La casualidad completa lo que la causalidad no alcanza. El amor frustrado o la insolación han causado la locura, pero puede no estar claro por qué una loca se cree una hortaliza u otra tiene manía persecutoria:

Hay tantas demencias como cabezas; nada indica cómo ha empezado esta demencia, cuáles son las que el vicio ha llevado al abismo y cuáles han sido arrastradas por la virtud. Nadie, si no sabe de antemano su historia, puede descifrar el origen de su desgracia en sus rostros desfigurados, sucios. Es el azar quien ha colgado las máscaras sobre esas frentes vacías. (Vallès, 1977: 92)

Pero aunque Vallès menciona el azar, el lector reconoce las causas que el narrador le invita a deducir líneas después: La loca que se cree un rábano trabajaba en el campo y la que se siente perseguida era saltimbanqui callejera; sus vivencias y el medio en que trabajaban nos orientan respecto al motivo por el que se manifiesta su locura en una u otra "máscara".

Sin discursos teóricos, en realidad, Vallès insinuaba la inexistencia del azar ontológico, el que forma parte del ser. Su determinismo es finalmente absoluto, pues el lector descubre líneas después que no hay aleatoriedad o espontaneidad, sino eventos desatendidos en el análisis inicial.

El conocimiento del destino, como decíamos, es intuitivo o mágico; en tanto que a las leyes de la causalidad que nos determinarían se accede a través de un proceso racional y lógico. El determinismo está ligado a la ley de la causalidad: No hay diversas posibilidades de causación, está de-terminado, es decir, fijado y establecido. Teniendo en común con el destino y la predestinación su inexorabilidad -con excepciones-, destino y predestinación conciernen a los hechos de los seres humanos o en relación con ellos, en tanto que el determinismo es universal, afecta a todos los fenómenos del universo no sólo a los humanos, e interpretado al modo en que los naturalistas decimonónicos lo hacían, atañe también al mundo nouménico de la libertad. Las acciones humanas, así entendidas, son fenómenos naturales sometidas al determinismo universal.

Para el determinista, no hay libertad ni libre albedrío. La idea de destino, como la de los estoicos, valora el modo en que cada cuál actúa respecto a su destino. Sin embargo, para el determinista la voluntad no puede sortear el fatalismo, es decir, su manifestación fenoménica. 


\section{CONCLUSIONES}

La escuela naturalista surge como plasmación artística de una filosofía común entre quienes se adscriben a ella. Partiendo de una ilimitada confianza en las ciencias, la tarea del novelista naturalista pasa a ser la del experimentador que anota fenómenos, teniendo en cuenta las disposiciones innatas, el medio físico y social y el momento histórico. Su tarea se concibe limitada por el desarrollo de unos planteamientos que escoge, pero que debe atenerse a aquello que la ciencia establezca que ha de suceder según esas leyes sociales y biológicas. Todo lo indeterminado queda fuera de las leyes científicas, por lo que se niega y lógicamente queda excluido de estas novelas.

Como veíamos, según esta postura filosófica y literaria, el determinismo es la ley que rige los fenómenos y explica al ser humano y su sociedad. En la novela naturalista radical, todo queda reducido a esas leyes. Y puesto que la literatura pasa a ser investigación del medio social, se convierte en vehículo ideológico y atiende a los sectores sociales menos libres, más determinados y oprimidos.

En la extensa red de factores determinantes de la existencia humana que esta novela recrea, la voluntad de los personajes no sirve para enfrentarse a lo que les está determinado, o sencillamente no existe. En consecuencia, esa ausencia desprovee de responsabilidad respecto a sus actos a quienes están científicamente reducidos a la superposición de leyes diversas. Los personajes se mueven por instinto y pulsión en una lucha por la supervivencia que aniquila hasta a los más fuertes, determinados por su medio embrutecedor, su herencia genética y por su clase y sexo, entre otros factores.

Como consecuencia lógica de este devastador cuadro, los naturalistas recreaban una visión de la existencia humana que fue considerada "fatalista". Por ello, Zola, atento a lo peyorativo de la irracional y poco científica creencia en un fatum, quiso matizar que el fatalismo de su novela era la manifestación "obligada" del determinismo. Es decir, el "fatum naturalista" constituye la manifestación necesaria de un fenómeno que expresa la misma falta de libertad, pero que es modificable. Sobre el fatalismo, en cambio, no se puede actuar, es determinación incondicional que excluye la razón y carece de relación causal comprensible -semejante al fatalismo moderno de Diderot-. El fatalismo determinista es consecuencia y no a priori, pero lo cierto es que el resultado literario es la misma falta de libertad con funestas consecuencias trágicas.

Desde sus inicios, la escuela naturalista resultó polémica. No obstante, el rechazo inicial a este tipo de novela lo fue por su forma, centrándose la discusión en lo estético y en el significado y límites del Arte. Otros intelectuales rechazaron, en cambio, su fondo filosófico. En ese sentido, el caso español es muy significativo. En nuestro contexto, un factor que limitó la influencia del naturalismo a elementos parciales de la escuela fue la inquebrantable fe de la mayoría de los intelectuales en el libre albedrío del ser humano. No en vano, este había sido tema frecuente de nuestro Siglo de Oro.

Las obras literarias aquí analizadas reflejan esa magnitud del poder del destino griego y de la determinación del naturalismo. Frente a estas fuerzas, los seres resultan insignificantes, y sus tragedias, nimiedades diluidas en la eternidad de una historia universal que transcurre sin detenerse a contemplar nuestra exigüidad. Ambas fuerzas 
son inexorables y nos someten inapelablemente, de ahí la semejanza aparente entre ambas. El destino raramente puede trastocarse -en contadísimas excepciones-, en tanto que la determinación niega las otras opciones. Pero es que además, la narración naturalista no se detendría a retratar lo excepcional, pues lo que interesa es el relato del cumplimiento de la ley. Y las apariencias vuelven a unir destino y determinación, dado que ambas nociones son fatalistas: la griega como previsión, la naturalista como fenómeno en que esas leyes se manifiestan.

Pero en tanto que el peso del destino es enfrentado por seres excepcionales héroes, dioses, reyes - , la narración determinista debe optar por aquellos que sean más comunes en su especie. Lógicamente, los primeros son los menos atados y más libres, en tanto que los personajes naturalistas han de ser quienes menos libertad y excepcionalidad puedan mostrar en la experimentación narrativa, supeditada al control necesario para confirmar la hipótesis de partida.

En el fondo, tanto unos como otros seres están en cierta medida "destinados". Los clásicos, porque creyendo en el destino, precipitan o encaminan su vida a ese cumplimiento. Los decimonónicos, porque creyéndolos sus narradores incapaces de la variación, se encaminan a ese destino de la hipótesis con que fueron seleccionados. La creencia en un devenir concreto coacciona e inclina a lo que se espera de ellos, haciéndolos partícipes tácitos o activos de su cumplimiento.

En cambio, destino y determinación difieren en el grado de libertad o de responsabilidad que conceden a los seres humanos. El destino provee a cada ser de un lote en que no todo está previsto y es más propio de causas finales, aunque se arrastre desde antes de nacer, como sucede con las maldiciones familiares. La determinación por leyes biológicas impera también desde antes del nacimiento, pero es permanente y afecta a todo. Siendo ambas anteriores al ser, sin embargo, la idea de la trascendencia deviene en actitudes diferentes. En tanto que el destino debe afrontarse con virtud, el determinista no admite tal término, pues los actos son consecuencia de la combinación de las leyes que causan unos $\mathrm{u}$ otros actos.

En tanto que el destino puede ser capricho de los dioses, la determinación obedece a la causalidad de unas leyes. Estas novelas deterministas propagan una idea concreta del ser humano, determinado por esas leyes de causación, y si algún fenómeno se escapa a ellas, obedece a que en la finitud de nuestro entendimiento, no alcanzamos a comprenderlas totalmente, pero no dejan de ser unas y no otras.

Tanto en el contexto griego clásico como en el que dio origen al naturalismo, la obra literaria no es meramente Arte, ni el escritor pretende solo ser artista. En pocas ocasiones, como a finales del siglo XIX pensamiento y arte estuvieron tan unidos. Más allá de la forma literaria, la novela decimonónica fue un eslabón en el debate sobre la libertad humana que divulgó una idea muy concreta de ella, y que seguiría debatiéndose en generaciones posteriores. Pero además, esta novela inició una forma de sumisión del arte a la ciencia, lo que constituye una contribución decisiva en el asentamiento de la subordinación de toda manifestación humana al cientifismo. 


\section{BIBLIOGRAFÍA}

Botrel, J.-F. (1988): “España, 1880-1890: El naturalismo en situación”, en Y. Lissorgues (ed.) (1988) Realismo y naturalismo en España en la segunda mitad del siglo XIX, Barcelona, Anthropos: 183-197.

Caudet, F. (1988): “La querella naturalista. España contra Francia”, en Y. Lissorgues (ed.) (1988) Realismo y naturalismo en España en la segunda mitad del siglo XIX, Barcelona, Anthropos: 58-70.

Caudet, F. (1991): Estudio preliminar a Zola, Trabajo, Madrid, Eds. de la Torre.

Ceárd, H. (2003): La sangría, en Zola et alii, Las veladas de Medán, Córdoba, Universidad de Córdoba, Servicio de Publicaciones.

Esquilo (1993): Tragedias completas, Barcelona, Planeta.

Goncourt, E. de (1998): La ramera Elisa, Madrid, Ágata.

Goncourt, E. y J. de (1990): Germinie Lacerteux, ed. de Mª Dolores Fernández Lladó, Madrid, Cátedra.

González Herrán, J. M. (1989): Estudio introductorio a Pardo Bazán, La cuestión palpitante, Barcelona, Anthropos.

Hennique, L. (2003): El asunto del número siete, en Zola [et al.], Las veladas de Medán, Córdoba, Universidad de Córdoba, Servicio de Publicaciones.

Huertas Llull, R. (1984): “La novela experimental y la ciencia positiva”, Revista de la Sociedad Española de Historia de las Ciencias y de las Técnicas, 7/ 13, 29-52.

Huertas Llull, R. (1985): “Psiquiatría, crimen y literatura (1): El criminal nato en el naturalismo zoliano", Revista de la Asociación Española de Neuropsiquiatría, V, 13, 132-150.

Huysmans, J.K. (1919): Allá lejos (Là-bas), versión española de G. Gómez de la Mata, pról. de V. Blasco Ibáñez, Valencia, Prometeo.

Huysmans, J.K. (2003): Con el petate a cuestas, en Zola [et al.], Las veladas de Medán, introd. E. Cobos Castro, Universidad de Córdoba, Servicio de Publicaciones, Córdoba / Mochila al hombro, en Zola, Maupassant, Daudet y otros, (1977) El cuento naturalista francés, ed. H. Cardoso, Buenos Aires, Centro Ed. de América Latina.

Huysmans, J.K. (s. f.): Las hermanas Vatard, pról. Blasco Ibáñez, Valencia, Prometeo.

Huysmans, J.K. (s. f.): Río abajo, en Apuntes parisienses, versión de G. Gómez de la Mata, Valencia, Prometeo, s.f.

Lissorgues, Y. (ed.) (1988): Realismo y naturalismo en España en la segunda mitad del siglo XIX, Barcelona, Anthropos.

López Jiménez, L. (1977): El naturalismo y España: Valera frente a Zola, Madrid, Alhambra. 
Maupassant, G. (2003a): "La génesis de este libro", en Zola et alii, Las veladas de Medán, introd. E. Cobos Castro, Córdoba, Universidad de Córdoba, Servicio de Publicaciones.

Maupassant, G. (2003b): Bola de sebo, en Zola et alii, Las veladas de Medán, introd. E. Cobos Castro, Córdoba, Universidad de Córdoba, Servicio de Publicaciones.

Maupassant, G. (1977): En familia, en Zola, Maupassant, Daudet y otros, (1977): El cuento naturalista francés, ed. H. Cardoso, Buenos Aires, Centro Ed. de América Latina

Martínez Torrón, D. (1987): "El naturalismo de La Regenta", Clarín y La Regenta en su tiempo, Oviedo, Universidad de Oviedo, 587-95.

Pardo Bazán, E. (1986): Los pazos de Ulloa, ed. M. Mayoral, Madrid, Castalia.

Pattison, W. (1969): El Naturalismo español. Historia de un movimiento literario, Madrid, Gredos.

Pérez Galdós, B. (2007): La desheredada, ed. José Antonio Fortes, Madrid, Akal.

Ruiz de Elvira, A. (1982): Mitología clásica, Madrid, Gredos.

Sófocles (1990): Tragedias completas, ed. de José Vara Donado, Madrid, Cátedra.

Valera, J. (1886): “Apuntes sobre el arte de escribir novelas. II", La Revista de España, 111, Madrid.

Vallès, J. (1977): Sainte-Anne, en Zola, Maupassant, Daudet y otros, (1977): El cuento naturalista francés, ed. H. Cardoso, Buenos Aires, Centro Ed. de América Latina.

Ynduráin, D. (2004): prólogo a Calderón, P., La vida es sueño, Madrid, Biblioteca Nueva.

Zola, E. (1972): Germinal, ed. de J. A. Gómez Marín, 2 vols., Madrid, Miguel Castellote.

Zola, E. (1989): El Naturalismo, ed. de Laureano Bonet, Barcelona, Península.

Zola, E. (1991): Trabajo, Madrid, Eds. de la Torre.

Zola, E. (1998): La taberna, edición de F. Caudet, Madrid, Cátedra.

Zola, E. (2001): Naná, ed. Fco. Caudet, Madrid, Cátedra.

Zola, E. (2002): La bestia humana, Sevilla, Renacimiento.

Zola, E. et alii. (2003): Las veladas de Medán, introd. E. Cobos Castro, Córdoba, Universidad de Córdoba, Servicio de Publicaciones.

Zola, E. (2003): El ataque del molino, en Zola [et al.], Las veladas de Medán, Córdoba, Universidad de Córdoba, Servicio de Publicaciones.

Zola, Maupassant, Daudet y otros, (1977): El cuento naturalista francés, ed. H. Cardoso, Buenos Aires, Centro Ed. de América Latina. 